\title{
The Measuring and Observation Tool in Sports
}

\author{
Julen Castellano and Abigail Perea \\ University of the Basque Country, Vitoria, Spain \\ LOREA ALDAY \\ Asociación de Estudios e Investigación en las Ciencias del Deporte (GIDE), Vitoria, Spain \\ AND \\ Antonio Hernández Mendo \\ Malaga University, Malaga, Spain
}

\begin{abstract}
The Measuring and Observation Tool in Sports (MOTS) has been designed to facilitate the systematic observation of sports. It is a user-friendly tool developed to help researchers observe, codify, register, and analyze any situation that occurs in a natural or habitual context in which behaviors are spontaneous. Users can define up to 12 mutually exclusive code sets and up to 120 different behaviors to facilitate data collection and can work with any observational data type: event sequences, event sequences over time, state sequences, interval sequences, or multievent sequences. MOTS plays digital video files, which allows for video and taxonomic tools to be displayed on the screen at the same time. The observations are registered automatically, including the time and duration of the event, in frames and seconds simultaneously. Furthermore, the data analysis feature allows the user to calculate the percentage of intervals, the frequency distributions, and the conditional probabilities.
\end{abstract}

The various techniques used for observation have clearly undergone a notable development. The original paper-and-pencil observations were first superseded by the use of tape recorders, and nowadays a wide range of sophisticated computer technology is available (Franks, Wilson, \& Goodman, 1987); for example, digitizing tables or voice recognition programs have made the tasks of researchers and observers much less arduous. Nevertheless, the large volume of data that may be recorded within the framework of observational methodology (Perea, 2008) has meant that the keenest of researchers have had to develop specific technologies for this purpose.

Numerous software applications have been designed using current technology in order to record perceivable behavior. In this regard, Darst, Zakrajsek, and Mancini (1989) listed several programs that were already being used up to 40 years ago for the observation of verbal and nonverbal behavior: FIAS (Flanders's Interaction Analysis System, from 1965), RANKIN (the Rankin Interaction Analysis System), BAT (Behavioral Analysis Tool), CAFIAS (Cheffers's adaptation of FIAS), CSFI (the CAFIAS Supervisory Feedback Instrument), DAC (the dyadic adaptation of CAFIAS), and CBRS (Coaching Behavior Recording System). Kahng and Iwata (1998) also described a series of computer applications, such as BOS (Behavior Observer System), which uses PDAs (the Apple Newton or USRobotics Pilot) to codify behavior with different onscreen buttons. Users can access the tools already created for a number of observational contexts, and they may also edit the tools or create new ones, choosing from a list of behaviors given by the system or writing directly over the buttons. These tools allow for up to 24 different responses to be codified during a session. Another system mentioned by Kahng and Iwata is PCS (Portable Computer Systems), which comprises recording programs and data analysis. The data recording program enables users to record frequency, duration, latency, and time between responses for up to 45 different events, and it can also capture data with discontinuous selection tests. Finally, the authors also mentioned SCOPE (Social Interaction Continuous Observation Program for Experimental Studies), which is capable of recording up to 21 different responses during an observation session, as well as recording the frequency and duration of responses.

Other programs currently available include ANSEC (Quera \& Estany, 1984), CASE (Computer Assisted Sports Evaluation; Franks \& Goodman, 1984), CABER (Capture and Analysis of Behavioral Events in Real Time; Patrick, 1985), SATS (Yoder \& Tapp, 1990), The Observer (Noldus, 1991), C-QUAL (Duncan \& Sayre, 1991), ODAP (Observational Data Acquisition Program; Hetrick, Isenhart, Taylor, \& Sandman, 1991), VideoNoter (Roschelle \& Goldman, 1991), SHAPA (James \& Sanderson, 1991), CAMERA (van der Vlugt, Kruk, van Erp, \& Geuze, 1992), EVENT-PC (Ha, 1992), TRANSCRIPTOR (Hernández Mendo, Ramos, Peralbo, \& Risso,

A. Perea, bigaper@hotmail.com 
1993), PROCODER (Tapp \& Walden, 1993), MOOSES (Multi-Option Observation System for Experimental Studies; Tapp, 1994), MacSHAPA (Sanderson et al., 1994), DATACAP (Emerson, 1995), DODS (Direct Observation Data System; Johnson et al., 1995), ProBES (Professional Behavior Evaluation System; Ricketts, 1995), VBA (Virtual Behavior Analyst; Winston, 1995), Theme (Magnusson, 1996), Theme Coder (PatternVision, 2001), VTLOGANL (Hecht \& Roberts, 1996), SDISGSEQ (Bakeman \& Quera, 1996), BEST (Sharpe \& Koperwas, 1999), DCA (Data Collection Assistant; Bluestem Technologies, 1997), ObsWin ("Observational data collection analysis for Windows"; Martin, Oliver, \& Hall, 1999), CODEX (Hernández Mendo, Bermúdez Rivera, Anguera, \& Losada, 2000), EBASS (Ecobehavioral Assessment System Software; Greenwood, Carta, \& Dawson, 2000), The Observer Video-Pro (Noldus, Trienes, Hendriksen, Jansen, \& Jansen, 2000), and CURIOUS (Gorospe, Anguera, Hernández Mendo, \& Saracho, 2001). Furthermore, two software tools are designed specifically for application to sports to enable perceivable behavior to be recorded: SOF-CODER (Jonsson, 2004) and SOCCAF (version 2.2) video (Perea, Alday, \& Castellano, 2006). In the latter software, the definition of variables is set by the program, but in both systems the recording of data follows the chronology of events. This variety notwithstanding, the tools available still leave certain areas unaddressed.

Reviewing these observational programs has, however, enabled us to identify a number of functionalities that were considered when developing the MOTS software application. For example, despite small differences between the applications we analyzed, a number of generalizations can be made about them. (1) The observations, recording, and analyses have their own modules, such that the access permitted by the programs to the video, the category system (which tends to be preset), and the data register is often not simultaneous. (2) The option for setting up and defining the codes of the observation tool may be closed or open; that is, the codes may be already defined by the application itself, or the user may be allowed to define them. (3) Depending on the application, the taxonomic system may be visible or hidden on the computer screen; in other words, in some programs it is necessary to open a drop-down menu to select the category, whereas in others the behaviors are visible onscreen. (4) In some programs, codes may be introduced using the mouse, whereas others only allow this operation via the keyboard; in some cases, it is also necessary to write the code each time a category occurs. (5) The software applications do not generally enable the simultaneous use of digital video while they are running. (6) The types of data that can be coded are not the same for all of the programs: Some are based on events and others on states or sequences (event sequences, state sequences, interval sequences, and multievent sequences), whereas some allow all types. (7) Time is not recorded by all of the applications. (8) In the analysis section, the descriptive statistics most commonly provided are absolute and relative frequencies, durations, some transitions, and some kind of concordance index, although not all of the programs include all of these.
Finally, (9) not all of the programs allow data to be exported to other applications.

\section{Characteristics of MOTS}

It is a fact that the different software tools we analyzed do not cover the needs of researchers. Indeed, the complexity of motor situations and the nature of competitive activity do not favor the use of "closed" software tools, in which the researcher needs to adapt the observational tool to the possibilities the application will encounter. MOTS was developed in order to satisfy all of the requirements that an application of this kind should fulfill:

User-friendliness. The video, observational tool, and registered data appear simultaneously on the screen. They are directly accessible, and no advanced computer skills are needed to use the application.

Possibility of customizing (ad hoc) the observational tool. Once it has been set up, the observational tool can be used immediately; up to 12 criteria and 120 categories can be defined. The names and number of the criteria, and the categories under each criterion, are directly defined by the user.

Automatic recording of the time at which an action takes place. When registering an event, the time and duration of the event are automatically saved, in frames and/or seconds, depending on the required accuracy.

The registered data are sequentially recorded, and thus, in addition to the typical analysis of frequencies, it is possible to conduct intensive diachronic studies - that is, to use any type of data: event sequences, event sequences over time, state sequences, and multievent sequences.

Direct linkage between video and events. The registered data are linked to the video frame in which the events were observed. The user can always access any part of the observed session, making it easy to search the behaviors that were observed and registered during the session.

Less time required for observation. Video and data registering are controlled through simple mouse clicks.

Higher data quality. The facts that the categories are defined and the registered data do not need to be transcribed help to avoid errors.

Simultaneous data analysis. The analysis tool automatically performs frequency and duration analyses (in frames and/or seconds). The user can also regroup the registered data according to classification levels - that is, by relating certain variables or features to one another (in the form of contingency tables, with two or more inputs).

The data files may be exported to the more commonly used statistical packages, such as SPSS for Windows, SDIS-GSEQ (Bakeman \& Quera, 1996), GT (version 2.0.E, for generalizability study; Ysewijn, 1996), and SAS (SAS Institute, 1999; Schlotzhauer \& Littell, 1997).

\section{Functional Structure of the MOTS Program}

Once the software has been installed, a new MOTS folder will appear under Programs on the Start menu. This folder contains the executable file and the user guide.

When starting MOTS, the main window will appear. From here, the user can access the three principal modules - Tool Design, Observation, and Analysis-by clicking with the mouse on the corresponding button. 
If there are any unsaved changes, MOTS will always ask the user to save them before closing. The program is only definitively closed when the Close $(\times)$ button at the upper right of the main window is clicked. At this point, any information that was not saved will be definitively lost. In the following sections, we describe the different modules of MOTS.

Setting criteria. Clicking on the Tool Design button in the main window causes a new window to be opened (see Figure 1), from which users can design their own observational tools, save them, or modify them.

When the module is opened, MOTS is ready to design a new observational tool. Observational tools include the following elements (see Figure 2): (1) Criterion ID, the unique identification number for each criterion; (2) Criterion Name, given to the observation criterion; (3) Category Name, unique for each category, which may have up to five characters; and (4) Description, which defines the meaning of the category (the use of this element is optional, although recommended).

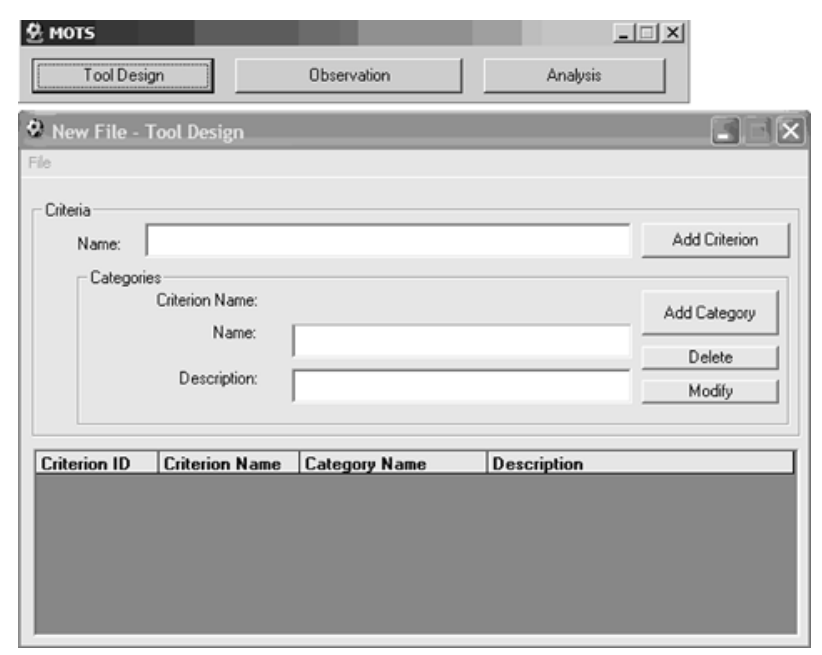

Figure 1. Criteria for the observational tool are set using the Tool Design window.

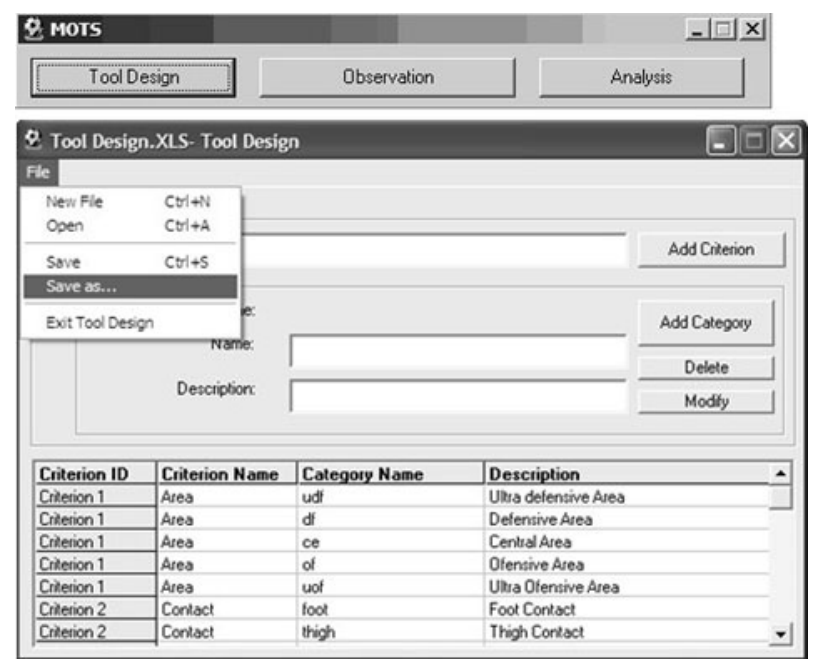

Figure 2. Saving the observational tool.
A new criterion is added by writing its name in the text box and clicking on Add Criterion. The name of the criterion will appear automatically in the Criteria frame. At this point, the categories for this criterion can be defined by writing a name and description (optional) and clicking on the Add Category button for each new category. A new row will be added to the table for each category.

Users may modify the categories by double clicking on the category to be modified. The values for this category will appear in the Category frame, in which the required modifications can be made. The modified category will be updated in the table by clicking on the Modify button.

A category can be deleted by double clicking on its row in the table and then clicking the Delete button. A criterion can be deleted by deleting all of the categories contained by this criterion.

Once the observational tool has been designed, users can save it as a Microsoft Excel document for subsequent use by clicking on the Save or Save as ... submenus in the File menu.

The observational tools are saved as Microsoft Excel files (see Figure 3) and may have up to 120 categories distributed across 12 criteria. Each criterion must contain at least one category, and no two criteria or two categories may have the same name.

Users may retrieve previously saved observational tools in order to visualize, modify, or save them again, either in the same or in a different location. A previously created observational tool can be opened by clicking Open in the File menu.

Observation. After clicking on the Observation button, a new window will appear. From here, users may open an observation tool, observe a sports event, and register their observations. The registered data may also be gathered, saved, retrieved, and modified.

The first step for registering the data is to select the observational tool that was previously created using the Tool Design functionality. The observational tool can be selected by clicking the Examine button. Once the observational tool has been selected, a new frame per each category and a new button per criterion will automatically appear on the screen (see Figure 4).

The Observation module allows users to reproduce AVI, MPEG, and MPG video files. The file to be reproduced can be selected by clicking on the Load Match submenu from the Match menu, located on the menu bar (see Figure 5).

Once the session to be observed has been selected, the user can play the video file by clicking the Play button. Of course, the typical buttons Previous (move the video to the previous track), Next (move the video to the next track), Pause, Rewind (move the image back $5 \mathrm{sec}$ ), Forward (move the image forward $5 \mathrm{sec}$ ), and Stop (the right mouse button can also be used to stop and restart the image) can also be used. There is also a slide bar for forwarding or rewinding the video in 1-min intervals.

Observation can begin once the observational tool has been selected and the video is running. If the user observes one of the events defined by the observational tool and wants to register it, he or she just needs to right click 


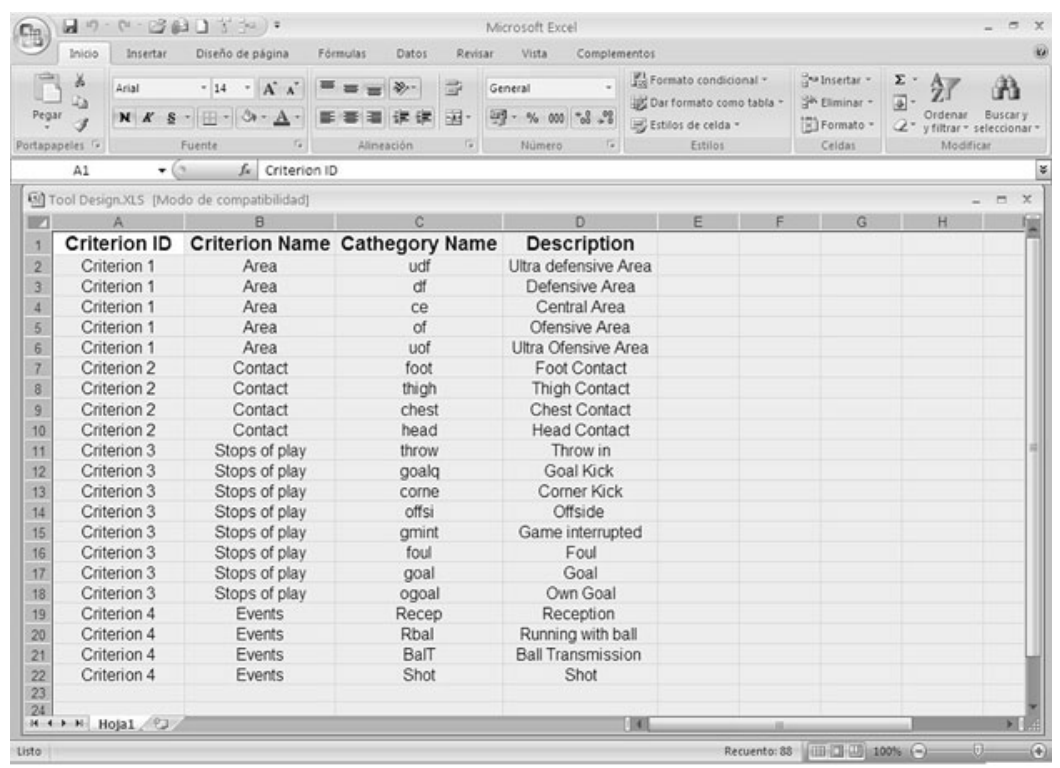

Figure 3. Microsoft Excel document containing the observational tool.

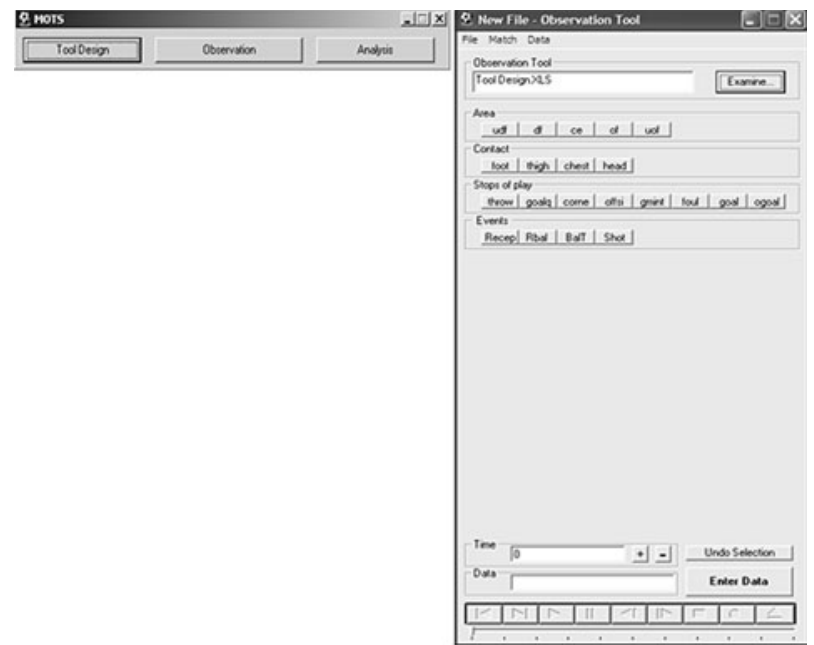

Figure 4. The Observation window.

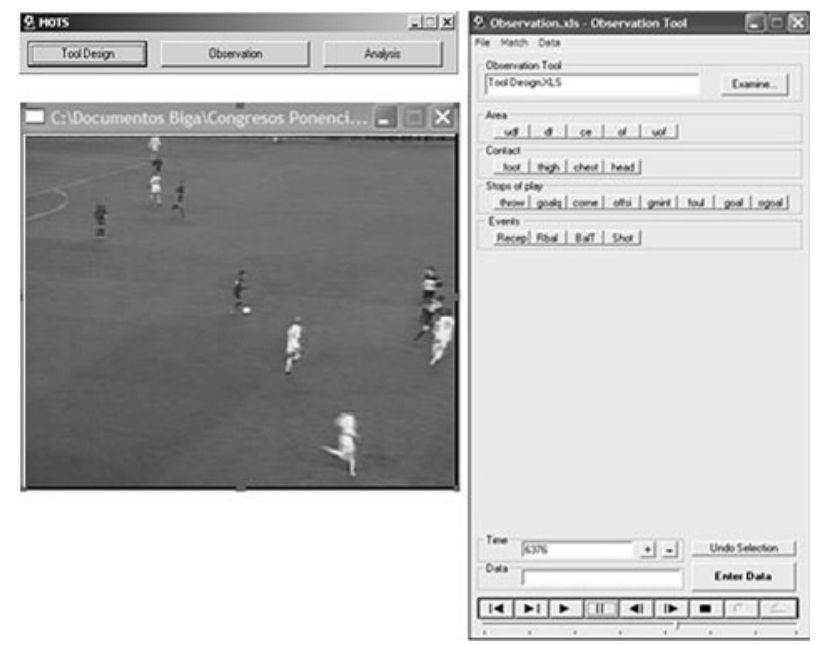

Figure 5. A sports match loaded for registering data. 


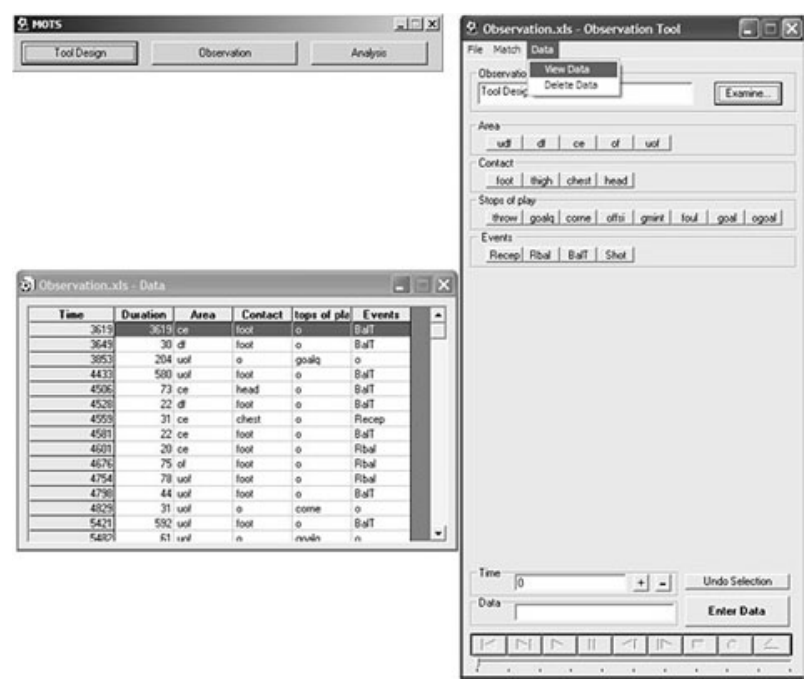

Figure 6. The Data window.

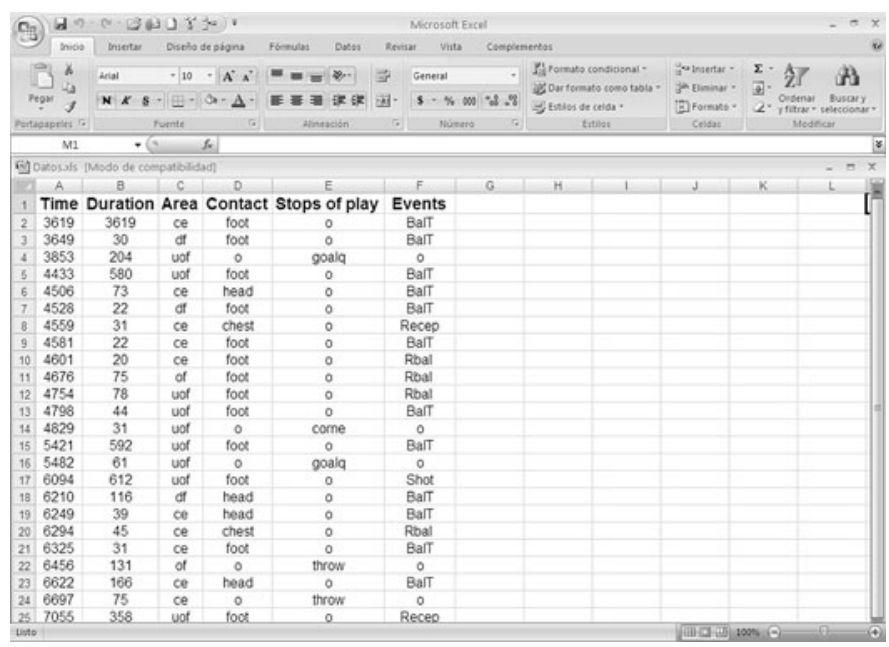

Figure 7. Microsoft Excel document containing the registered data.
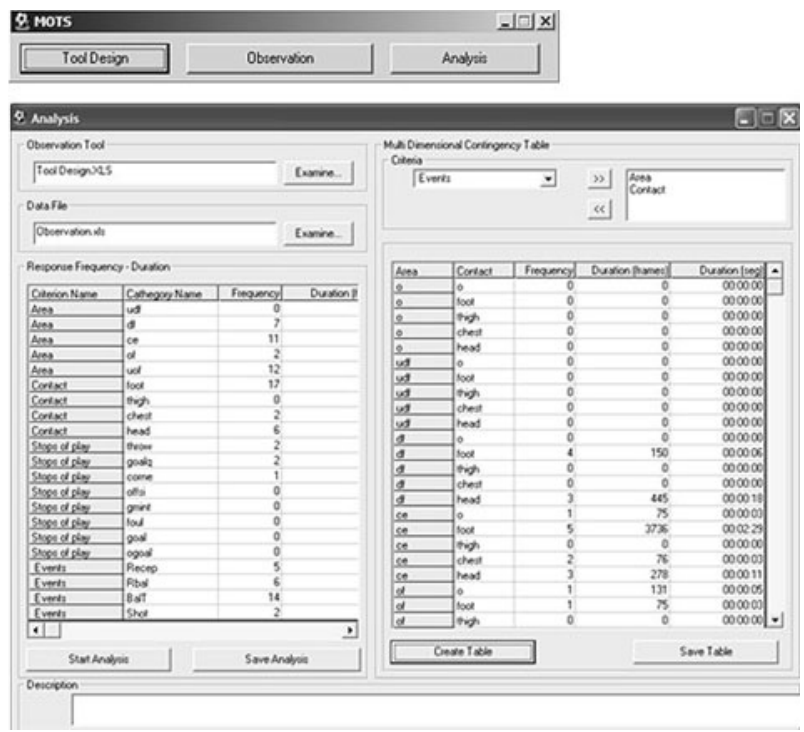

Figure 8. The Analysis window. 


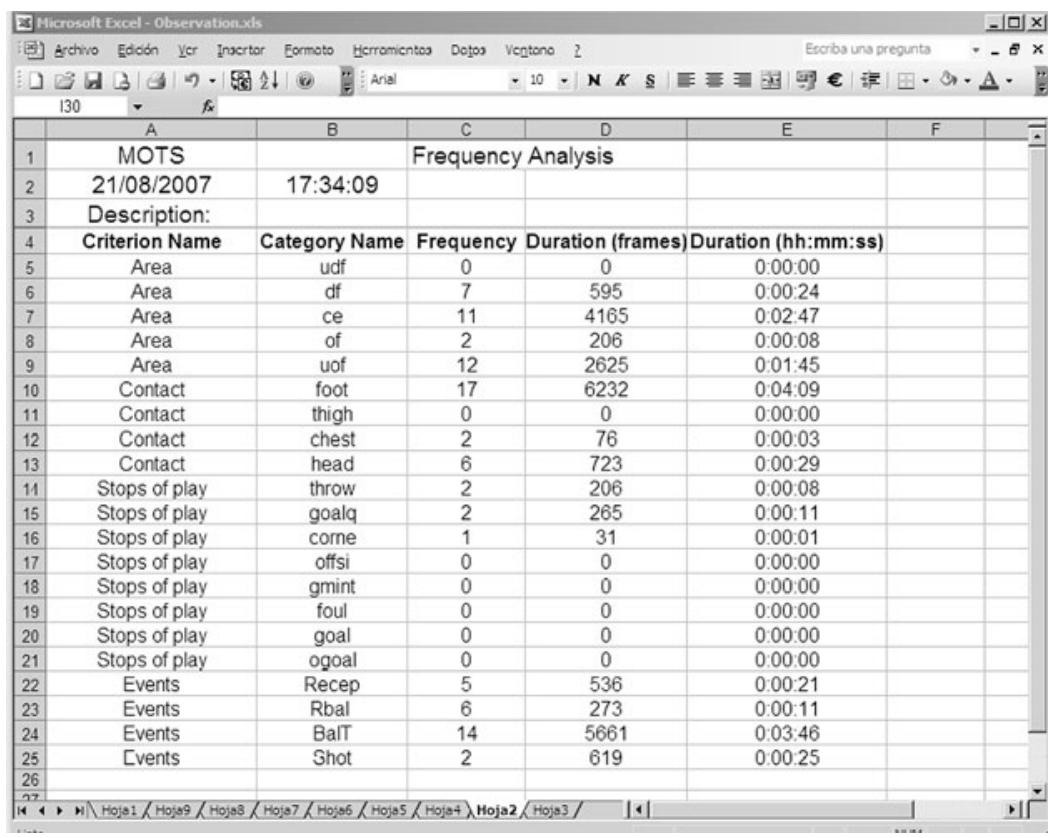

Figure 9. Microsoft Excel document containing the frequency analysis of the data.

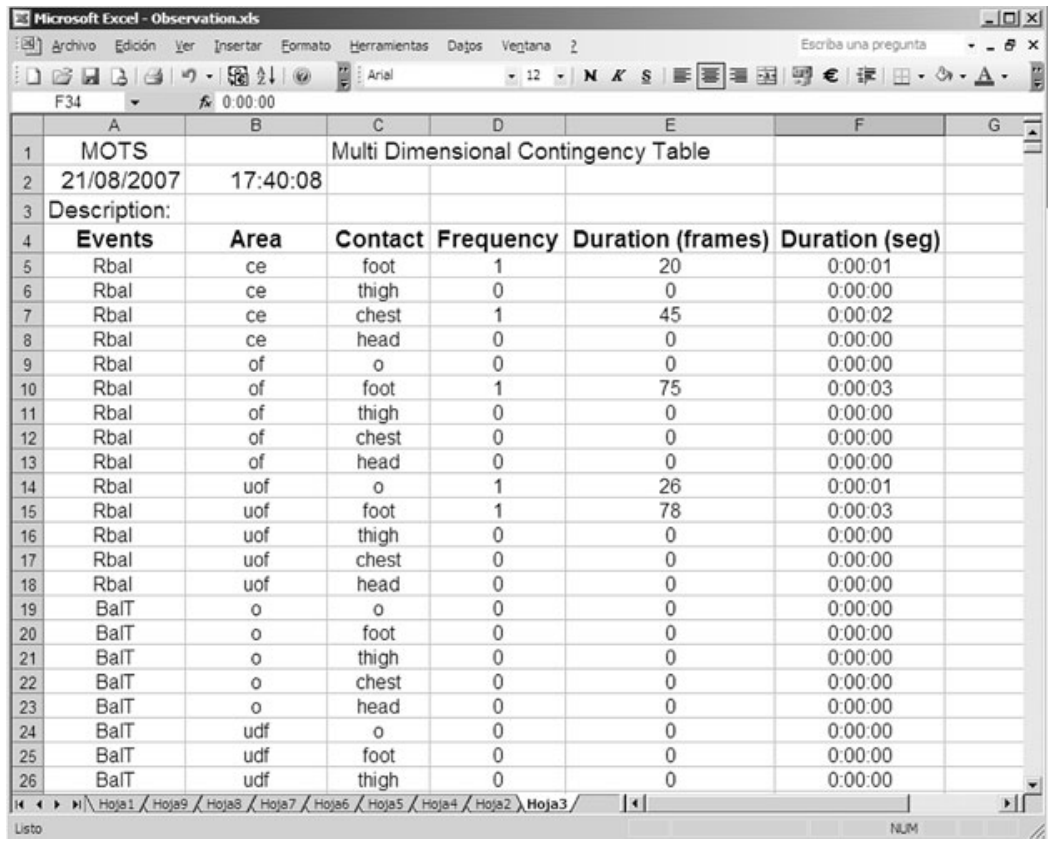

Figure 10. Microsoft Excel document containing the contingency table of the data. 
with the mouse to freeze the image and click on the category buttons that correspond to the observed events. If the Enter Data button is clicked, the data will be definitively registered, and the image will start running again so the registering session can continue. Should more than one category be selected within the same criterion, a pop-up error message will appear.

The registered data and the time at which the action occurred will appear in the Data window (see Figure 6). By double clicking on one of the rows of the table, the user can move in the video file to the instant at which the event was observed.

The program stores the registered data in an Excel file. These files can be saved by clicking on Save or Save as ... in the File menu. The program enables users to delete erroneous observations by clicking on Delete Data in the Data menu. This operation will delete from the table the last observation (row) added by the user.

Since the data registering cannot always be done in a single session, and more than one session may be required to complete the observation, MOTS enables users to retrieve the data files and continue with the observation and data registering from the point at which they left off. Files are retrieved simply by clicking on Open in the File menu and selecting the file with the registered data. The registered data are stored in Excel files in which each row corresponds to one register, including the time in frames at which the event was observed, the duration of the event (in frames), and the categories of the observed criteria (see Figure 7).

Data analysis. The Analysis feature will appear when the researcher clicks the Analysis button of the main window; from here, frequency and duration analyses of the registered data can be performed simultaneously with the data registering.

A frequency or duration analysis can be performed by selecting the data file to be analyzed (the one containing the registered data) and the observational tool used, along with the observation, and then clicking on the Start Analysis button. The results will automatically appear on the screen (see the left side of Figure 8). Users should bear in mind that the analysis may take several seconds, or even minutes, depending on the amount of data to be analyzed.

As a second option, the registered data may be regrouped by levels of classification ( $n$-level contingency tables) - in other words, certain variables or features may be related to one another. This is particularly useful when working with sequences or multievents. Users can relate as many criteria as are available in the observational tool and can carry out the operation as many times as they wish (see the right side of Figure 8).

Once the data analysis is complete, the results can be saved by clicking the Save Analysis button. The analysis will be saved in worksheets within the Excel file where the registered data were stored (see Figures 9 and 10).

\section{AUTHOR NOTE}

We gratefully acknowledge the support of the University of the Basque Country (EHU/UPV; Grant NUPV06/30) for the period 2007-2008, and that of the Dirección General de Investigación, Ministerio de Ciencia y Tecnología (DGES; Grant SEJ2005-01961/PSIC) for the period 2005-2008. MOTS is commercial software. Correspondence relating to this article may be sent to A. Perea, University of the Basque Country, Vitoria, Spain (e-mail: bigaper@hotmail.com).

\section{REFERENCES}

BaKeman, R., \& Quera, V. (1996). Análisis de la interacción: Análisis secuencial con SDIS y GSEQ. Madrid: RA-MA.

Bluestem Technologies (1997). Data Collection Assistant [Software]. Overland Park, KS: Author.

Darst, P. W. Zakrajsek, D. B., \& Mancini, V. H. (1989). Analyzing physical education and sport instruction (2nd ed.). Champaign, IL: Human Kinetics.

DUNCAN, S., JR., \& SAYRE, R. E. (1991). C-QUAL: A system for computeraided transcription of videotaped action sequences. Behavior Research Methods, Instruments, \& Computers, 23, 505-512.

EMERSON, E. (1995). DATACAP [Software]. Manchester, U.K.: University of Manchester, Hester Adrian Research Centre.

Franks, I. M., \& GoOdMAN, D. (1984). A hierarchical approach to performance analysis. Science Periodical on Research \& Technology in Sport, GY-1.

Franks, I. M., Wilson, G. E., \& Goodman, D. (1987). Analyzing a team sport with the aid of computers. Canadian Journal of Sport Sciences, 12, 120-125.

Gorospe, G., Anguera, M. T., Hernández Mendo, A., \& Saracho, L. (2001). Desarrollo de una herramienta informática de carácter general para la codificación y registro de hechos observacionales: Corious 1.0 (Proyecto de Investigación Kirola Ikertuz). Vitoria, Spain: Instituto Vasco de Educación Física.

Greenwood, C. R., Carta, J. J., \& Dawson, H. (2000). Ecobehavioral Assessment System Software (EBASS): A system for observation in education settings. In T. Thompson, D. Felce, \& F. Symons (Eds.), Behavioral observation: Technology and applications in developmental disabilities (pp. 229-251). Baltimore: Brookes.

HA, J. (1992). EVENT-PC [Software]. Seattle: University of Washington.

Hecht, J. B., \& Roberts, N. K. (1996). VTLOGANL: Coding and analyzing videotaped data. Behavior Research Methods, Instruments, \& Computers, 28, 76-82.

Hernández Mendo, A., Bermúdez Rivera, M. A., Anguera, M. T., \& LosADA, J. L. (2000). CODEX: Un programa informático para codificación de registros observacionales. Lecturas: Educación Física y Deportes, Revista Digital, 5, 18. Available at www.sportquest.com/ revista/efd18/codex.htm.

Hernández Mendo, A., Ramos, R., Peralbo, M., \& Risso, A. (1993). Un programa para el análisis observacional: Transcriptor v1.1, aplicación en psicología del deporte. Revista de Entrenamiento Deportivo, $7,18-25$

Hetrick, W. P., Isenhart, R. C., Taylor, D. V., \& Sandman, C. A (1991). ODAP: A stand-alone program for observational data acquisition. Behavior Research Methods, Instruments, \& Computers, 23, 66-71.

JAMES, J. M., \& SANDERSON, P. M. (1991). Heuristic and statistical support for protocol analysis with SHAPA Version 2.01. Behavior Research Methods, Instruments, \& Computers, 23, 449-460.

Johnson, H., Blackhurst, A. E., Maley, K., Bomba, C., Cox-Cruey, T., \& Dell, A. (1995). Development of a computer-based system for the unobtrusive collection of direct observational data. Journal of Special Education Technology, 7, 291-300.

Jonsson, G. K. (2004, November). SOF-CODER: Technological and multimedia system for recording data in soccer. Paper presented at the III. Congreso Vasco del Deporte, Vitoria, Spain.

Kahng, S. W., \& Iwata, B. A. (1998). Computerized systems for collecting real-time observational data. Journal of Applied Behavior Analysis, 31, 253-261.

Magnusson, M. S. (1996). Hidden real-time patterns in intra- and interindividual behavior: Description and detection. European Journal of Psychological Assessment, 12, 112-123.

Martin, N., Oliver, C., \& Hall, S. (1999). ObsWin: Observational data collection and analysis for Windows. CTI Psychology Software News, 9, 14-16.

Noldus, L. P. J. J. (1991). The Observer: A software system for collec- 
tion and analysis of observational data. Behavior Research Methods, Instruments, \& Computers, 23, 415-429.

Noldus, L. P. J. J., Trienes, R. J. H., Hendriksen, A. H. M., Jansen, H., \& JANSEN, R. G. (2000). The Observer Video-Pro: New software for the collection, management, and presentation of time-structured data from videotapes and digital media files. Behavior Research Methods, Instruments, \& Computers, 32, 197-206.

PATRICK, J. (1985). The CABER system. In Proceedings of the 8th Australian Computer Science Conference. Melbourne, Australia.

PatternVision (2001). Theme Coder [Software]. Retrieved January 15, 2002, from www.patternvision.com.

Perea, A. (2008). Análisis de las acciones colectivas en el fútbol de rendimiento. Doctoral dissertation, Universidad del País Vasco, Vitoria, Spain.

Perea, A., Alday, L., \& Castellano, J. (2006). Aplicación informática específica para la observación de la acción de juego en fútbol. In J. Castellano Paulis, L. M. Sautu Apellaniz, A. Blanco Villaseñor, A. Hernández Mendo, A. Goñi Grandmontagne, \& F. Martínez de Ilarduya (Eds.), Evaluación e intervención en el ámbito deportivo (pp. 285-294). Vitoria, Spain: Diputación Foral de Álava.

QueRA, V., \& ESTANY, E. (1984). ANSEC: A BASIC package for lag sequential analysis of observational data. Behavior Research Methods \& Instrumentation, 16, 303-306.

RICKETTS, R. (1995). Professional Behavior Evaluation System (ProBES) [Software]. Abilene, TX: Author.

Roschelle, J., \& GoldMan, S. (1991). VideoNoter: A productivity tool for video data analysis. Behavior Research Methods, Instruments, \& Computers, 23, 219-224.

Sanderson, P. M., Scott, J. J. P., Johnston, T., Mainzer, J., WATANABE, L. M., \& JAMES, J. M. (1994). MacSHAPA and the enterprise of exploratory sequential data analysis (ESDA). International Journal of Human-Computer Studies, 41, 633-681.

SAS Institute (1999). SAS/STAT user's guide (Version 7.1). Cary, NC: Author.

Schlotzhauer, S. D., \& Littell, R. C. (1997). SAS system for elementary statistical analysis (2nd ed.). Cary, NC: SAS Institute.

Sharpe, T., \& Koperwas, J. (1999). BEST: Behavioral Evaluation Strategy and Taxonomy [Software]. Thousand Oaks, CA: Sage.

TAPP, J. (1994). MOOSES: Multiple option observation system for experimental studies. Unpublished manuscript, Vanderbilt University, Nashville, TN.

TAPP, J., \& WALDEN, T. (1993). PROCODER: A professional tape control, coding, and analysis system for behavioral research using videotape. Behavior Research Methods, Instruments, \& Computers, 25, 53-56.

van der Vlugt, M. J., Kruk, M. R., van Erp, A. M. M., \& Geuze, R. H. (1992). CAMERA: A system for fast and reliable acquisition of multiple ethological records. Behavior Research Methods, Instruments, \& Computers, 24, 147-149.

Winston, M. (1995). Virtual Behavior Analyst [Software]. Coral Springs, FL: World Enabling Resources.

Yoder, P. J., \& TAPP, J. T., SR. (1990). SATS: Sequential analysis of transcripts system. Behavior Research Methods, Instruments, \& Computers, 22, 339-343.

YsEwIJN, P. (1996). GT: Software for generalizability studies. Available online at www.irdp.ch/methodo/generali.htm.

(Manuscript received November 25, 2007; revision accepted for publication February 1, 2008.) 